\title{
Phosphine-Catalyzed Intermolecular Acylfluorination of Alkynes via a $P(V)$ Intermediate
}

\author{
Hayato Fujimoto, ${ }^{1}$ Takuya Kodama, ${ }^{1}$ Masahiro Yamanaka ${ }^{2}$ and Mamoru Tobisu*,1 \\ ${ }^{1}$ Department of Applied Chemistry, Graduate School of Engineering, Osaka University, Suita, Osaka 565-0871, Japan \\ ${ }^{2}$ Department of Chemistry, Faculty of Science, Rikkyo University, 3-34-1 Nishi-Ikebukuro, Toshima-ku, Tokyo 171-8501, \\ Japan
}

\section{Supporting Information Placeholder}

\begin{abstract}
We report on the phosphine-catalyzed intermolecular carbofluorination of alkynes using acyl fluorides as fluorinating reagents. This reaction promises to be a useful method for the synthesis of highly substituted monofluoroalkene derivatives, since acyl fluorides can be easily prepared from the corresponding carboxylic acid derivatives and the reaction proceeds under ambient conditions without the need for a transition-metal catalyst. Experimental and computational studies indicate that a five-coordinated fluorophosphorane is involved as the key intermediate in the fluorination step.
\end{abstract}

Fluorinated molecules occupy an important place in the pharmaceutical, medicinal, agrochemical and material sciences. ${ }^{1}$ Among the various fluorinated motifs, monofluoroalkene derivatives are of particular interest, partly because of their utility as a peptide bond isostere. $^{2}$ Therefore, novel, straightforward methods for the synthesis of monofluoroalkenes via $\mathrm{C}-\mathrm{F}$ bond formation are in great demand. ${ }^{3}$ The carbofluorination of alkynes, which proceeds via the concomitant formation of $\mathrm{C}-\mathrm{C}$ and $\mathrm{C}-\mathrm{F}$ bonds, is a powerful method for the synthesis of monofluoroalkenes. Although some methods for the catalytic carbofluorination of alkynes have recently been developed, ${ }^{4}$ these methods are restricted to intramolecular reactions in which transition-metal catalysts and highly electrophilic $\mathrm{F}^{+}$reagents, such as Selectfluor and NFSI (Scheme 1a) are used. Herein we report on the phosphine-catalyzed intermolecular carbofluorination of alkynes via the $\mathrm{C}-\mathrm{F}$ bond-forming ligand coupling of a $\mathrm{P}(\mathrm{V})$ intermediate (Scheme $1 \mathrm{~b}$ ).

In recent years, ligand coupling on $\mathrm{P}(\mathrm{V})$ species $^{5}$ has attracted renewed interest as an alternative to transition-metal mediated cross-coupling reactions. For example, McNally and coworkers reported on the ligand coupling of pyridine derivatives on a $\mathrm{P}(\mathrm{V})$ species which was generated by the reaction of heterocyclic phosphonium salts with heteronucleophiles ${ }^{6}$ (Scheme 1c) and heterobiaryl synthesis via a $\mathrm{P}(\mathrm{V})$ intermediate. $^{7}$ Vilotijevic and coworker also reported on the ligand coupling of benzothiazole derivatives on a $\mathrm{P}(\mathrm{V})$ species. $^{8}$ Despite the significant advances in $\mathrm{P}(\mathrm{V})$-mediated reactions over the past years, a $\mathrm{P}(\mathrm{V})$-mediated $\mathrm{C}-\mathrm{F}$ bond-formation reaction have not been achieved. ${ }^{9}$

Quite recently, we reported on the first synthesis of a stable tetraarylfluorophosphorane by the reaction of fluorine-substituted phosphines with an aryne via tandem nucleophilic addition and nucleophilic aromatic substitution (Scheme 1d). ${ }^{10}$
Scheme 1. Carbofluorination of Alkynes: Background and Working Hypothesis
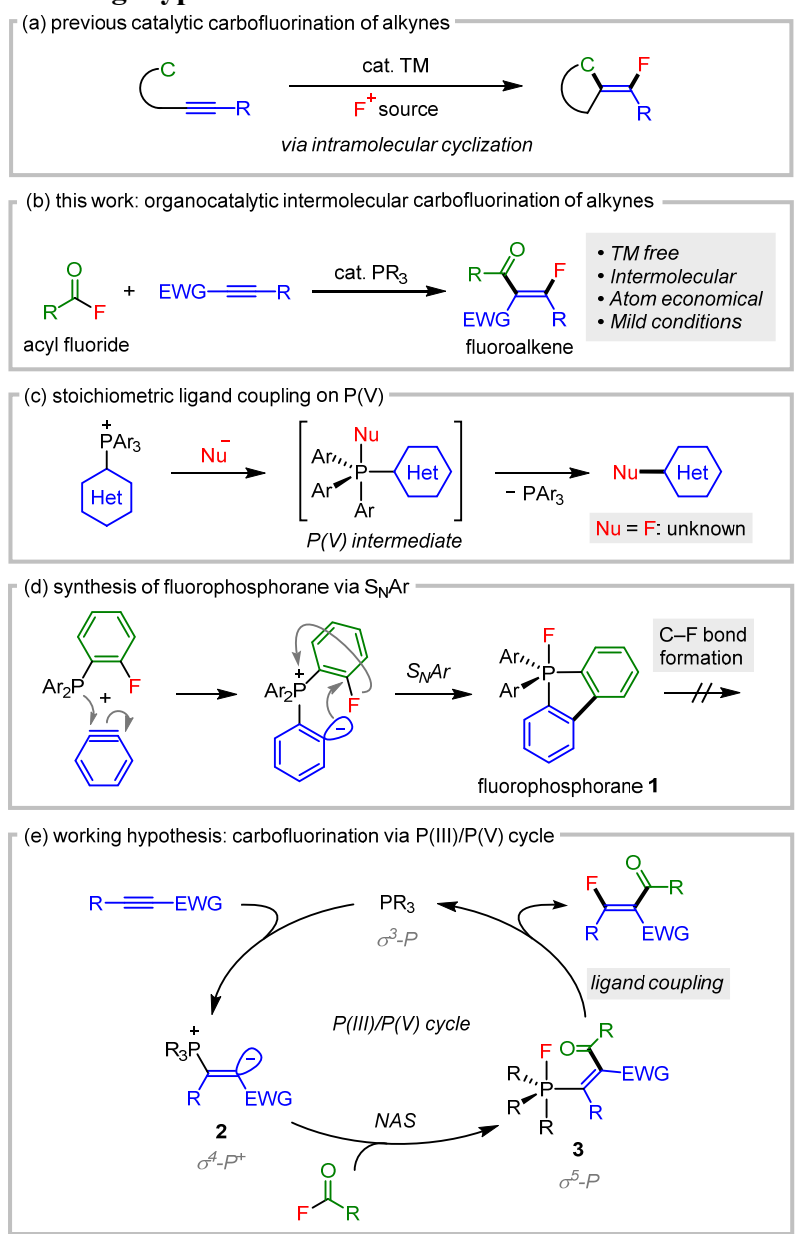

Phosphine-mediated C-F bond formation would be possible if the ligand coupling from the fluorophosphorane $\mathbf{1}$ were to take place. However, all of our attempts to achieve ligand coupling of $\mathbf{1}$ were unsuccessful. We envisaged that increasing the electrophilicity of the equatorial ligand in the fluorophosphorane derivative would permit this unprecedented $\mathrm{C}-\mathrm{F}$ bond forming ligand cou- 
pling on $\mathrm{P}(\mathrm{V})$ to be successful. Based on this hypothesis, we designed phosphine-catalyzed carbofluorination of alkynes via a $\mathrm{P}(\mathrm{III}) / \mathrm{P}(\mathrm{V})$ manifold (Scheme 1e). It is well known that phosphines add, not only to an aryne, but also to an electron-deficient alkyne such as an alkynoate to form a carbanion species. ${ }^{11}$ If the resulting carbanion $\mathbf{2}$ is sufficiently nucleophilic to react with an acyl fluoride, the fluorophosphorane 3 would be formed by nucleophilic acyl substitution (NAS). The fluorophosphorane $\mathbf{2}$ has an equatorial ligand bearing electron-withdrawing groups, which we hypothesized would facilitate ligand coupling to form a C-F bond with the regeneration of the phosphine catalyst.

To verify the feasibility of our hypotheses, we initially examined the reaction between the acyl fluoride $\mathbf{4 a}$ and alkynoate 5a using different phosphines and NHCs (Table 1). Intensive screening resulted in identifying $\mathrm{PCy}_{3}$ as a uniquely effective catalyst, whereas other phosphines and $N$-heterocyclic carbenes failed to promote this carbofluorination. Thus, the reaction of $\mathbf{4 a}$ (1.5 equiv) with $\mathbf{5 a}$ in the presence of $\mathrm{PCy}_{3}(30 \mathrm{~mol} \%)$ in toluene at room temperature afforded the monofluoroalkene $6 \mathbf{a a}$ in $74 \%$ isolated yield. A ${ }^{19} \mathrm{~F}$ NMR analysis indicated that the carbofluorination product was formed as a 1:1.2 mixture of $E: Z$ isomers. The isomers interconverted by the reversible addition-elimination of $\mathrm{PCy}_{3}$ under the catalytic conditions used (see Scheme S1) ${ }^{12}$ thus leading to the formation of the thermodynamically more stable $Z$ isomer as the major product. ${ }^{13,14}$ In addition to the fact that this reaction represents the first intermolecular carbofluorination, it features the use of acyl fluorides both as acylating and fluorinating reagents in an atom-economical manner, which is also unprecedented.

Table 1. Catalyst Optimization for Carbofluorination between $4 a$ and $5 a^{a}$

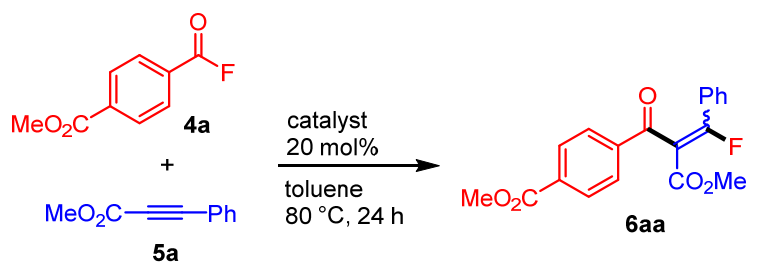

\begin{tabular}{ccc|} 
entry & catalyst & yield (\%) \\
1 & $\mathrm{PCy}_{3}$ & 52 \\
$2^{b}$ & $\mathrm{PCy}_{3}$ & $76(74) E: Z=1: 1.2$ \\
3 & $\mathrm{P}^{n} \mathrm{Bu}_{3}$ & 0 \\
4 & $\mathrm{P}^{t} \mathrm{Bu}_{3}$ & 0 \\
5 & $\mathrm{PAd}_{3}$ & 0 \\
6 & $\mathrm{PAd}_{2}{ }^{n} \mathrm{Bu}$ & 0 \\
7 & $\mathrm{PPhMe}_{2}$ & 0 \\
8 & $\mathrm{PPhCy}_{2}$ & 0 \\
9 & $\mathrm{PCyp}$ & 4 \\
10 & $\mathrm{DCYPE}$ & 6 \\
11 & $\mathrm{IPr}$ & 0
\end{tabular}
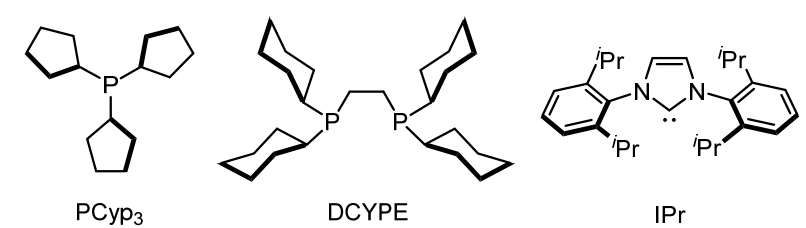

${ }^{a} \mathbf{4 a}(0.30 \mathrm{mmol}), 5 \mathbf{a}(0.20 \mathrm{mmol}), \mathrm{PCy}_{3}(0.04 \mathrm{mmol})$ and toluene $(1.0 \mathrm{~mL})$ in sealed tube at $80{ }^{\circ} \mathrm{C}$ for $24 \mathrm{~h} .{ }^{b}$ Reaction conducted at room temperature in the presence of $\mathrm{PCy}_{3}(0.06 \mathrm{mmol})$. Yield of isolated products are shown in parentheses. $E: Z$ ratios were determined by ${ }^{19} \mathrm{~F}$ NMR analysis.

With the optimized reaction conditions in hand, we subsequently examined the scope of the carbofluorination reactions (Scheme 2). Regarding acyl fluorides, electron-neutral (4b) as well as electrondeficient substrates bearing trifluoromethyl (4c), nitro (4d), cyano (4e), and benzoyl (4f) groups readily participated in this reaction to produce the corresponding monofluoroalkenes. Halogens such as iodo $(\mathbf{4 g})$, bromo (4h) and chloro (4i) groups were compatible, allowing the resulting monofluoroalkenes to be amenable to further structural elaboration via common $\mathrm{C}-\mathrm{X}$ bond functionalization reactions. Acyl fluorides bearing heteroaryl $(\mathbf{4 j})$ and $\pi$-extended aryl (4k) groups also underwent the carbofluorination successfully. Alkynoates bearing methyl (5b), methoxy (5c), fluoro (5d), bromo (5e), chloro (5f) groups reacted to afford the corresponding monofluoroalkenes. Although alkynoates bearing alkyl groups, such as methyl 2-octynoate failed to form the corresponding carbofluorinated product, the 3-thienyl (5g) and 2-pyridyl substituted alkynoate $(\mathbf{5 h})$ were compatible. Interestingly, when $\mathbf{5 h}$ was used, products $\mathbf{6 j h}, \mathbf{6}$ ah and 6ih with a high $Z$ selectivity were obtained. ${ }^{15}$ The structure of $6 \mathbf{j h}$ was confirmed by single-crystal X-ray analysis. ${ }^{16}$ This carbofluorination proceeded when alkynes bearing a different electron-withdrawing group such as ethyl ester (5i), $t$-butyl ester $(\mathbf{5 j})$ and benzoyl $(\mathbf{5 k})$ groups were used instead of the methyl ester $\mathbf{5 a}$, affording the corresponding coupling products $\mathbf{6 j i - 6 j k}$. This organocatalyic carbofluorination can be used in the late-stage functionalization of pharmaceuticals containing a carboxylic acid functionality, such as probenecid and febuxostat to form the corresponding monofluoroalkene derivatives 6la and 6ma.

To gain additional insights into the reaction mechanism, some control experiments were performed (Scheme 3). Apart from the mechanism shown in Scheme 1e, an alternative pathway that is initiated by the reaction of $\mathrm{PCy}_{3}$ with the acyl fluoride is also possible. This would lead to the formation of an acylphosphonium fluoride, which could function as a fluoride ion source to induce the subsequent addition to the alkynoate to form the fluoroallenoate $\mathbf{7}$ as a key intermediate. ${ }^{17}$ However, external fluoride sources, such as $\mathrm{CsF}$ and tetrabutylammonium difluorotriphenylsilicate (TBAT) failed to promote the carbofluorination of $\mathbf{4} \mathbf{a}$ and $\mathbf{5 a}$, thus excluding the alternative fluoride-mediated mechanism (Scheme 3a). In an attempt to observe the postulated fluorophosphorane intermediate $\mathbf{3}$, the reaction of $\mathbf{4 a}$ and $\mathbf{5 a}$ in toluene- $d_{8}$ using 1.0 equiv of $\mathrm{PCy}_{3}$ was monitored by ${ }^{19} \mathrm{~F}$ NMR spectroscopy (Scheme $3 \mathrm{~b}$ ). However, no resonances assignable to $\mathrm{P}(\mathrm{V})$ species were observed and $\mathbf{6 b a}$ was formed in $43 \%$ yield $(E: Z=1.6: 1)$, indicating that the rate of ligand coupling of $\mathbf{3}$ is rapid compared with that of the formation of $\mathbf{3}$. When the same reaction was conducted in $\mathrm{CD}_{3} \mathrm{CN}$, instead of toluene- $d_{6}$, 6ba was not formed in an appreciable amount and instead, $\mathrm{PCy}_{3} \mathrm{~F}_{2}(8)$ and the hydroacylated product 9 were produced in $28 \%$ and $34 \%$ yields, respectively. $\mathrm{R}_{4} \mathrm{PF}$-type compounds can exist as both four-coordinate ionic (phosphonium fluoride) and five-coordinate neutral (fluorophosphorane) species, wherein a phosphonium fluoride form is more stable in polar solvents. ${ }^{18}$ Therefore, the fluorophosphorane 3 ionizes in $\mathrm{CD}_{3} \mathrm{CN}$ thus making it susceptible to undergoing dispropotionation, ${ }^{19}$ which would eventually lead to the formation of $\mathbf{8}$ and $\mathbf{9}$ via protonation. These results suggest that phosphonium fluoride is not a competent intermediate for $\mathrm{C}-\mathrm{F}$ bond formation. 
Scheme 2. Scope of the Phosphine-Catalyzed Carbofluorination of Alkynoates ${ }^{a}$

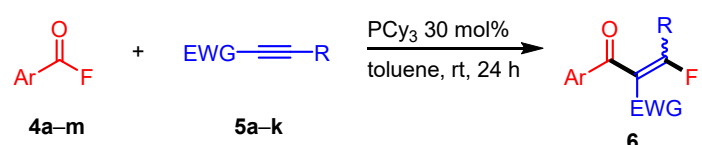

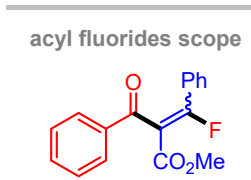

6ba $61 \%(1: 1)$

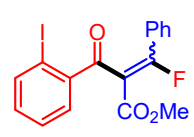

6ga $70 \%(1: 1)$<smiles>CC(=O)C(C(=O)c1ccc(F)cc1)=C(F)F</smiles>

6ca $79 \%(1: 1.1)$<smiles>COC(=O)C(C(=O)O)C(=O)c1ccc([N+](=O)[O-])cc1</smiles>

6da $53 \%(1: 1.1)$

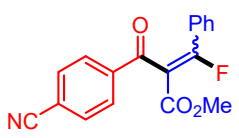

6ea $71 \%(1: 1.2)$<smiles>CCCCOC(=O)C(C(=O)c1ccc(C(=O)c2ccccc2)cc1)=C(F)c1ccccc1</smiles><smiles>COC(=O)C(=O)c1ccc(Cl)cc1</smiles>

$6 \mathbf{i a} 75 \%(1: 1)$

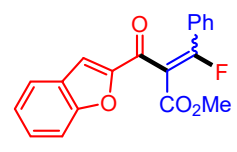

6ja $81 \%(1: 1.6)$

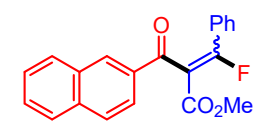

6ka $83 \%(1: 1.1)$

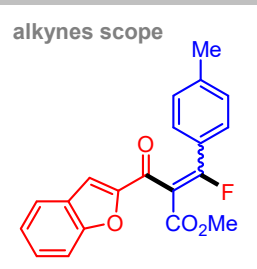

6jb $88 \%(1: 1.6)$

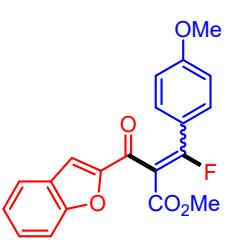

6jc $94 \%(1: 1.4)$

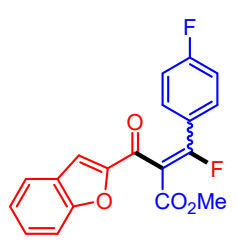

6jd $78 \%(1: 1.3)$<smiles>O=C(OC(=O)C(F)(F)c1ccc(Br)cc1)c1cc2ccccc2o1</smiles>

6je $60 \%(1: 1.2)$

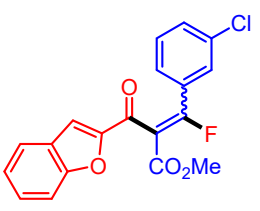

6jf $66 \%(1: 1)$

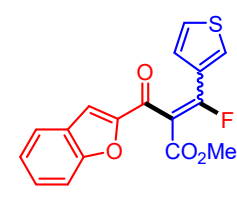

6jg $77 \%(1: 1.4)$

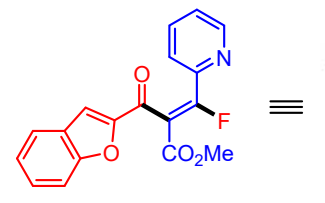

6jh 91\% (>1:99)

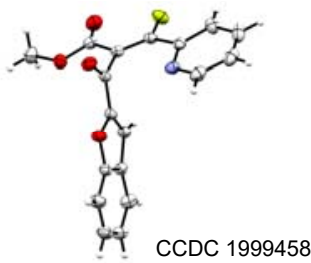<smiles>COC(=O)c1ccc(C(=O)C(=C(C)O)C(F)(F)c2ncccn2)cc1</smiles>

6ah 58\% (4:96)<smiles>COC(=O)C(C(=O)c1ccc(Cl)cc1)=C1CCCN1</smiles>

6ih 54\% (3:97)

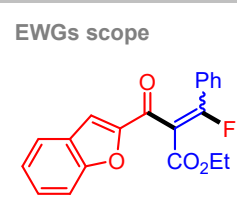

6ji 79\% (1:1.2)

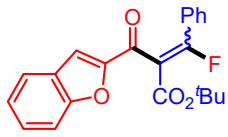

6jj 30\% (1:1)

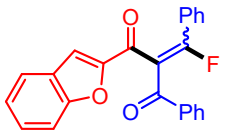

6jk 78\% (1:1) pharmaceuticals scope<smiles>CCCN(CCC)S(=O)(=O)c1ccc(C(=O)C(=C(F)c2ccccc2)C(OC)OC)cc1</smiles>

6la $91 \%(1: 1.1)$
from Probenecid

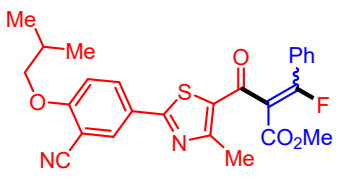

6ma $51 \%^{b}(1: 1.4)$

${ }^{a}$ Acyl fluoride $(0.30 \mathrm{mmol})$, alkyne $(0.20 \mathrm{mmol}), \mathrm{PCy}_{3}(0.06 \mathrm{mmol})$ and toluene $(1.0 \mathrm{~mL})$ in a sealed tube at room temperature for $24 \mathrm{~h}$. Yields of isolated products are shown. $E: Z$ ratios were determined by ${ }^{19} \mathrm{~F}$ NMR analysis and are shown in parentheses. ${ }^{b}$ Reaction at $50{ }^{\circ} \mathrm{C}$.

\section{Scheme 3. Control Experiments}

(a)

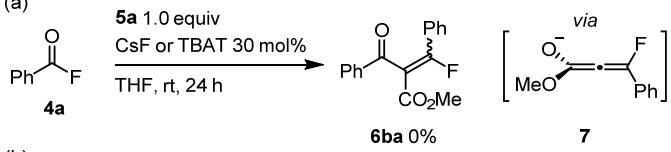

(b)

$$
\underset{4 a}{\stackrel{\mathrm{O}}{\mathrm{O}} \underset{\mathrm{F}}{\stackrel{\mathrm{PC} 1.0 \text { equiv }}{\mathrm{PC}_{3} 1.0 \text { equiv }}}}
$$

(c)

6ba $43 \%(E: Z=1.6: 1)$

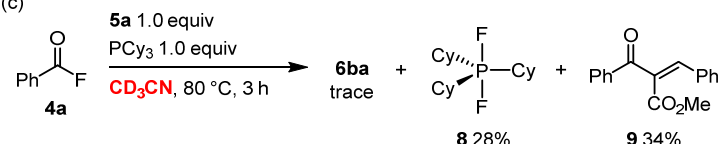

To further verify the intermediacy of fuluorophosphorane 3 in the PCy3-catalyzed carbofluorination, DFT calculations ( $\omega$ B97X-D/6$31+\mathrm{G}(\mathrm{d}, \mathrm{p})$ ) were conducted for the C-F bond-forming ligand coupling process (Scheme 4). INT1 and INT1' are the most stable fluorophosphoranes among the suite of isomers, having a trigonal bipyramidal geometry in which fluorine occupies the apical position. ${ }^{9,10,20}$ Because INT1 and INT1' have nearly the same energy ( $\Delta G=-0.3 \mathrm{kcal} / \mathrm{mol})$, INT1 and INT1' can be interconverted by a Berry pseudorotation mechanism with a low activation barrier. ${ }^{21}$ These phosphorane intermediates were found to be more stable than the corresponding phosphonium forms when toluene was used as a solvent (see Scheme S3). C-F bond formation from the INT1 occurs in a stepwise fashion, similar to the $\mathrm{C}-\mathrm{C}$ bond-forming ligand coupling of a $\mathrm{P}(\mathrm{V})$ intermediate. ${ }^{\mathrm{a}}$ In the $\mathrm{C}-\mathrm{F}$ bond forming 
step, an apical P-F bond breaks, allowing the fluorine atom to migrate to the equatorial $\beta$-carbon (TS1) to form the zwitterionic intermediate INT2. In the $\mathrm{C}-\mathrm{P}$ bond breaking step, fluorinated product $(E)$-P is generated by the dissociation of $\mathrm{PCy}_{3}$. This energy diagram indicates that the process from INT1 to $(E)$-P is a reversible process (highest activation barrier for the reverse reaction: $\Delta G^{*}=$ $21.7 \mathrm{kcal} / \mathrm{mol}$ ), which leads to the $E / Z$ isomerization of the product. ${ }^{22}$ Considering that the addition of a phosphine to an alkyne has a high activation barrier $(\sim 19 \mathrm{kcal} / \mathrm{mol}),{ }^{13}$ the ligand coupling process $(\sim 8.5 \mathrm{kcal} / \mathrm{mol})$ would be relatively facile. This view is consistent with the failure to observe a fluorophosphorane intermediate, such as INT1 (Scheme 3b).

\section{Scheme 4. Calculated Energy Diagrams for the Ligand Coupling of a Phosphorane Intermediate}

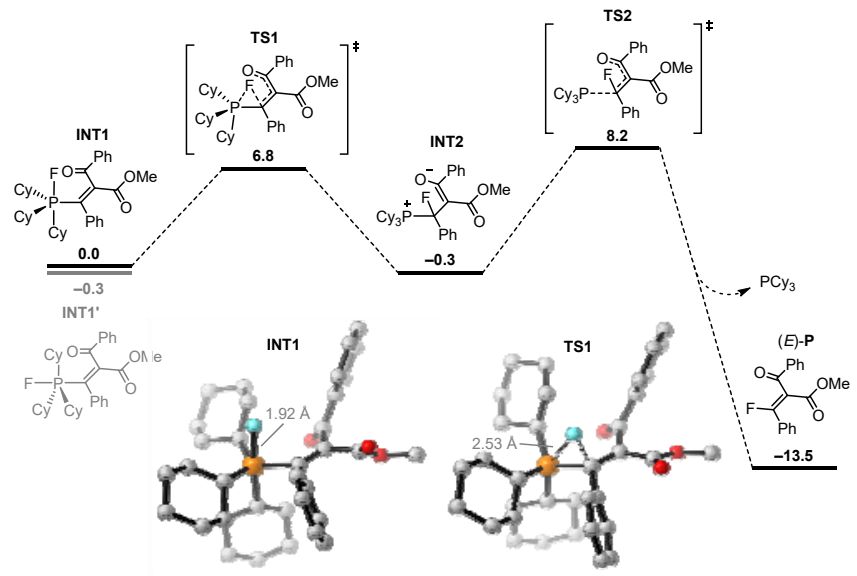

A synthetic advantage of acid fluorides is that they are directly accessible from the corresponding carboxylic acids and acyl chlorides. Phosphine-catalyzed carbofluorination can be performed using an acyl fluoride produced in situ from the acyl chloride $\mathbf{1 0}$ with $\mathrm{KF}$ to afford monofluoroalkene $6 \mathbf{c a}$ in $57 \%$ yield on a gram-scale.

\section{Scheme 5. Gram-Scale Reaction Using an Acyl Chloride} with KF

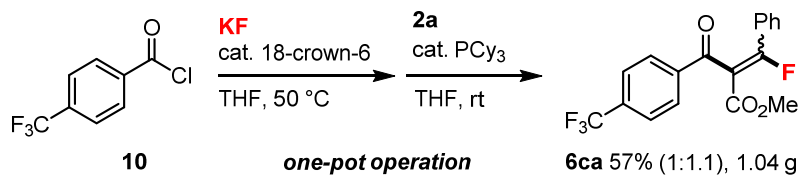

In conclusion, we report on the first catalytic intermolecular carbofluorination reaction. This reaction operates under mild conditions and in the absence of metals, thus showing a wide functional group tolerance. DFT calculations revealed that a $\mathrm{C}-\mathrm{F}$ bond is formed via ligand coupling on a phosphorus, which has not been achieved to date. ${ }^{9}$ The development of novel fluorination reactions using the fluorophosphorane platform are currently being investigated in our laboratory.

\section{ASSOCIATED CONTENT}

\section{Supporting Information}

The Supporting Information is available free of charge on the ACS Publications website.
Detailed experimental procedures, characterization of new compounds and computational details (PDF)

Compound 6jh crystal structure (CIF)

\section{AUTHOR INFORMATION}

\section{Corresponding Author}

*tobisu@chem.eng.osaka-u.ac.jp

Notes

The authors declare no competing financial interests.

\section{ACKNOWLEDGMENT}

This work was supported by JSPS KAKENHI (18H01978) and Scientific Research on Innovative Area "Hybrid Catalysis" (20H04818) from MEXT, Japan. MT thanks the Hoansha Foundation for their financial support. HF thanks JSPS Research Fellowship for Young Scientists and the Program for Leading Graduate Schools: "Interactive Materials Science Cadet Program." for their support. We also thank the Instrumental Analysis Center, Faculty of Engineering, Osaka University, for their assistance with HRMS

\section{REFERENCES}

(1) Review: (a) Shimizu, M.; Hiyama, T. Modern Synthetic Methods for Fluorine-Substituted Target Molecules. Angew. Chem. Int. Ed. 2004, 44, 214-231. (b) Müller, K.; Faeh, C.; Diederich, F. Fluorine in Pharmaceuticals: Looking Beyond Intuition. Science 2007, 317, 1881-1886. (c) Purser, S.; Moore, P. R.; Swallow, S.; Gouverneur, V. Fluorine in medicinal chemistry. Chem. Soc. Rev. 2008, 37, 320-330. (d) Wang, J.; Sánchez-Roselló, M.; Aceña, J. L.; del Pozo, C.; Sorochinsky, A. E.; Fustero, S.; Soloshonok, V. A.; Liu, H. Fluorine in Pharmaceutical Industry: Fluorine-Containing Drugs Introduced to the Market in the Last Decade (2001-2011). Chem. Rev. 2014, 114, 2432-2506.

(2) Champagne, P. A.; Desroches, J.; Hamel, J.-D.; Vandamme, M.; Paquin, J.-F. Monofluorination of Organic Compounds: 10 Years of Innovation. Chem. Rev. 2015, 115, 9073-9174.

(3) (a) Landelle, G.; Bergeron, M.; Turcotte-Savard, M.-O.; Paquin, J.-F Synthetic approaches to monofluoroalkenes. Chem. Soc. Rev. 2011, 40, 2867-2908. (b) Yanai, H.; Taguchi, T. Synthetic Methods for Fluorinated Olefins. Eur. J. Org. Chem. 2011, 5939-5954. (c) Besset, T.; Poisson, T.; Pannecoucke, X. Direct Vicinal Difunctionalization of Alkynes: An Efficient Approach Towards the Synthesis of Highly Functionalized Fluorinated Alkenes. Eur. J. Org. Chem. 2015, 2765-2789.

(4) (a) Peng, H.; Liu, G. Palladium-Catalyzed Tandem Fluorination and Cyclization of Enynes. Org. Lett. 2011, 13, 772-775. (b) Zhang, J.; Wang, H.; Ren, S.; Zhang, W.; Liu, Y. Cu(0)/Selectfluor System-Mediated Mild Synthesis of Fluorinated Fluorenones from Nonaromatic Precursors (1,6Enynes) Involving C-C Single Bond Cleavage. Org. Lett. 2015, 17, 2920 2923. (c) Tian, Q.; Chen, B.; Zhang, G. Silver-initiated radical ring expansion/fluorination of ethynyl cyclobutanols: efficient synthesis of monofluoroethenyl cyclopentanones. Green Chem. 2016, 18, 6236-6240.

(5) Early examples: (a) Mann, F. G.; Watson, J. Conditions of Salt Formation in Polyamines and Kindred Compounds. Salt Formation in the Tertiary 2-Pyridylamines, Phosphines, and Arsines. J. Org. Chem. 1948, 13 , 502-531. (b) Newkome, G. R.; Hager, D. C. A New Contractive Coupling Procedure. Convenient Phosphorus Expulsion Reaction. J. Am. Chem. Soc. 1978, 100, 5567-5568. (c) Uchida, Y.; Kozawa, H. Formation of 2,2'-Bipyridyl by Ligand Coupling on the Phosphorus Atom. Tetrahedron Lett. 1989, 30, 6365-6368. (d) Uchida, Y.; Onoue, K.; Tada, N.; Nagao, F.; Kozawa, H.; Oae, S. Reactions of 2-Pyridyl Substituted Phosphine Oxides and Phosphonium Salts with Organometallic Reagents and in Aqueous Media. Heteroat. Chem. 1990, 1, 295-306.

(6) (a) Hilton, M. C.; Dolewski, R. D.; McNally, A. Selective Functionalization of Pyridines via Heterocyclic Phosphonium Salts. J. Am. Chem. Soc. 2016, 138, 13806-13809. (b) Anderson, R. G.; Jett, B. M.; McNally, A. A Unified Approach to Couple Aromatic Heteronucleophiles to Azines and Pharmaceuticals. Angew. Chem. Int. Ed. 2018, 57, 12514-12518. 
(7) (a) Hilton, M. C.; Zhang, X.; Boyle, B. T.; Alegre-Requena, J. V.; Paton, R. S.; McNally, A. Heterobiaryl synthesis by contractive $\mathrm{C}-\mathrm{C}$ coupling via $\mathrm{P}(\mathrm{V})$ intermediates. Science 2018, 362, 799-804. (b) Boyle, B. T.; Hilton, M. C.; McNally, A. Nonsymmetrical Bis-Azine Biaryls from Chloroazines: A Strategy Using Phosphorus Ligand-Coupling. J. Am. Chem. Soc. 2019, $141,15441-15449$.

(8) Zi, Y.; Schomberg, F.; Wagner, K.; Vilotijević, I. C-H Functionalization of Benzothiazoles via Thiazol-2-yl-phosphonium Intermediates. Org. Lett. 2020, 22, 3407-3411.

(9) Levy, J. N.; Alegre-Requena, J. V.; Liu, R. Paton, R. S.; McNally, A. Selective Halogenation of Pyridines Using Designed Phosphine Reagents. J. Am. Chem. Soc. in press. (DOI:10.1021/jacs.0c04674).

(10) Fujimoto, H.; Kusano, M.; Kodama, T.; Tobisu, M. Aryne-Induced $\mathrm{S}_{\mathrm{N}} \mathrm{Ar} /$ Dearylation Strategy for the Synthesis of Fluorinated Dibenzophospholes from Triarylphosphines via a P(V) Intermediate. Org. Lett. 2020, 22, 2293-2297.

(11) Review: Guo, H.; Fan, Y. C.; Sun, Z.; Wu, Y.; Kwon, O. Phosphine Organocatalysis. Chem. Rev. 2018, 118, 10049-10293.

(12) Phosphine-catalyzed isomerization of alkenes: (a) Larpent, C.; Meignan, G. Chemistry in water - Part VI Catalytic isomerization and stereochemistry of reduction of acetylenics mediated by water-soluble phosphines. Tetrahedron Lett. 1993, 34, 4331-4334. (b) Murayama, H.; Nagao, K.; Ohmiya, H.; Sawamura, M. Phosphine-Catalyzed Vicinal Acylcyanation of Alkynoates. Org. Lett. 2016, 18, 1706-1709. (c) Pierce, B. M.; Simpson, B. F.; Ferguson, K. H.; Whittaker, R. E. Phosphine-mediated partial reduction of alkynes to form both $(E)$ - and $(Z)$-alkenes. Org. Biomol. Chem. 2018, 16, 6659-6662.

(13) Wang, W.; Wang, Y.; Zheng, L.; Qiao, Y.; Wei, D. A DFT Study on Mechanisms and Origin of Selectivity of Phosphine-Catalyzed Vicinal Acylcyanation of Alkynoates. ChemistrySelect 2017, 2, 5266-5273.

(14) The $E$ isomer is the major product at the initial stage of this reaction (cf. Scheme 3c). This result indicates that the $E$ form is preferentially formed and that it isomerizes to the thermodynamically more stable $Z$ form under the reaction conditions used.

(15) Computational experiments indicate that the pyridine-substituted $Z$ form products are stabilized by stereoelectronic interactions between nitrogen lone pair and an $\pi^{*} \mathrm{c}=0$ orbital (see Scheme S2).
(16) Crystal data for $\mathbf{6 j h}$, monoclinic, space group $P 2_{1} / c$ (no. 14), $a=$ 6.91739(14) $\AA, b=23.4940(4) \AA, c=9.63136(19) \AA, \beta=104.644(2)^{\circ}, V=$ $1514.42(5) \AA^{3}, T=123 \mathrm{~K}, Z=4, R_{1}\left(\mathrm{w} R_{2}\right)=0.0379(0.1075)$ for $899 \mathrm{pa}-$ rameters and 19566 unique reflections. GOF $=1.048$. CCDC 1999458.

(17) (a) Chambers, R. D.; Musgrave, W. K. R.; Partington, S. Fluoride-ioninitiated reactions of acetylenes. J. Chem. Soc. D 1970, 1050-1051. (b) Chambers, R. D.; Greenhall, M. P. Reactions involving fluoride ion: Part 46. Reactions of dialkyl acetylenedicarboxylates. J. Fluor. Chem. 2001, 107, $171-176$.

(18) (a) Schmidbaur, H.; Mitschke, K.-H.; Weidlein, J. Tetraorganofluorphosphorane. Angew. Chem. 1972, 84, 165-166. (b) Schmidbaur, H.; Mitschke, K.-H.; Buchner, W.; Stühler, H.; Weidlein, J. Tetraorganofluorphosphorane, R4PF. Chem. Ber. 1973, 106, 1226-1237. (c) Kornath, A.; Neumann, F.; Oberhammer, H. Tetramethylphosphonium Fluoride: "Naked" Fluoride and Phosphorane. Inorg. Chem. 2003, 42, 2894-2901.

(19) (a) Ter-Gabrielyan, E. G.; Gambaryan, N. P.; Knunyants, I. L.; Reaction of perfluoroisobutylene with tributylphosphine. Russ. Chem. Bull. 1981, 30, 301-304. (b) Arévalo, A.; Tlahuext-Aca, A.; Flores-Álamo, M.; García, J. J. On the Catalytic Hydrodefluorination of Fluoroaromatics Using Nickel Complexes: The True Role of the Phosphine. J. Am. Chem. Soc. 2014, 136, 4634-4639. (c) Facundo, A. A.; Arévalo, A.; Fundora-Galano, G.; FloresÁlamo, M.; Orgaz, E.; García, J. J. Hydrodefluorination of functionalized fluoroaromatics with triethylphosphine: a theoretical and experimental study. New J. Chem. 2019, 43, 6897-6908.

(20) Fluorine is known as an atom with one of the highest apicophilicity: Schmutzler, R. Chemistry and Stereochemistry of Fluorophosphoranes. Angew. Chem., Int. Ed. 1965, 4, 496-508.

(21) Moc, J.; Morokuma, K. AB Initio Molecular Orbital Study on the Periodic Trends in Structures and Energies of Hypervalent Compounds: FiveCoordinated XH5 Species Containing a Group 5 Central Atom (X = P, As, $\mathrm{Sb}$, and Bi). J. Am. Chem. Soc. 1995, 117, 11790-11797.

(22) The activation barrier for the addition of $\mathrm{PCy}_{3}$ to (Z)-P is $22.7 \mathrm{kcal} / \mathrm{mol}$, which also makes its isomerization energetically feasible under the reaction conditions used. The energy difference between $(E)$-P and $(Z)-\mathbf{P}$ is small, which is consistent with the $E / Z$ ratio of the products obtained experimentally (see SI for details). 